\title{
An Outsourced Health-enhancing Physical Activity Program for People with Rheumatoid Arthritis: Study of the Maintenance Phase
}

\author{
Birgitta Nordgren, Cecilia Fridén, Ingrid Demmelmaier, Gunnar Bergström, Ingrid E. Lundberg, \\ Thomas Nessen, Alyssa B. Dufour, and Christina H. Opava, for the PARA Study Group
}

\begin{abstract}
Objective. To describe changes of health-enhancing physical activity (HEPA), health perception, and functioning during the second year of a 2-year support program, determine aspects of adherence and response, and describe perceptions of the program.

Methods. Out of 220 individuals with rheumatoid arthritis (RA), 177 participated in the followup. Group support, strength training, and moderate-intensity aerobic activity were encouraged. Data collection included HEPA, perceived health, functioning, and perceptions of the program. Participants with unchanged/improved general health perception and at least 2 of aerobic capacity, grip strength, or timed standing were considered responders.

Results. Current and maintained HEPA decreased from $82 \%$ to $75 \%(\mathrm{p}=0.0141)$ and from $41 \%$ to $27 \%$ ( $\mathrm{p}<0.0001)$ during the second year. Minor declines in quality of life and activity limitation occurred ( $\mathrm{p}=0.0395$ and 0.0038 , respectively), while outcome expectations for benefits of physical activity increased $(\mathrm{p}=0.0010$ and 0.0186$)$ and waist circumference tapered off $(\mathrm{p}=0.0070)$. Strength training was performed on average 41 and 35 times among responders $(\mathrm{n}=54)$ and nonresponders $(n=105)$, respectively $(p=0.2708)$; HEPA 194 and 171 days, respectively $(p=0.0828)$; and support group meetings 12 and 10 times, respectively $(\mathrm{p}=0.0943)$. Strength training, aerobic activity, and short text message reminders were perceived as most valuable; step registration and the self-monitoring walk tests were less appreciated.

Conclusion. About one-fourth of the originally sedentary individuals with RA sustained their new HEPA behaviors after 2 years and most improvements of health and functioning were sustained. Structured use of behavior change techniques and a second year to support maintenance with a reduced program might help patients with RA to sustain HEPA behavior. (First Release May 1 2018; J Rheumatol 2018;45:1093-1100; doi:10.3899/jrheum.171002)
\end{abstract}

Key Indexing Terms: CLINICAL TRIAL

\section{EXERCISE}

\section{FOLLOWUP STUDY}

Health-enhancing physical activity (HEPA) is recommended to every adult as part of a healthy lifestyle, to reduce the risk of major diseases and premature death ${ }^{1,2}$. Older individuals and those with chronic conditions such as arthritis represent no exceptions, but they are advised to perform moderate-intensity aerobic activity for a minimum of $30 \mathrm{~min}$ for 5 days each week or vigorous-intensity aerobic activity for a minimum of $20 \mathrm{~min}$ for 3 days each week; in addition,
From the Division of Physiotherapy, Department of Neurobiology, Care Sciences and Society, Karolinska Institutet, Huddinge; Functional Area Occupational Therapy and Physiotherapy, Allied Health Professionals' Function, Karolinska University Hospital; Unit of Intervention and Implementation Research for Worker Health, Institute of Environmental Medicine, Karolinska Institutet; Rheumatology Unit, Department of Medicine, Karolinska University Hospital, Solna, Karolinska Institutet, Stockholm, Sweden; Harvard Medical School; Beth Israel Deaconess Medical Center, Boston, Massachusetts, USA

This study was funded by the Swedish Research Council, Forte Foundation, Combine Sweden, the Swedish Rheumatism Foundation, the

Norrbacka-Eugenia foundation, the Strategic Research Program in Health Care Science, and the National Postgraduate School of Health Care Sciences.

B. Nordgren, PhD; Division of Physiotherapy, Department of Neurobiology, Care Sciences and Society, Karolinska Institutet, and Functional Area Occupational Therapy and Physiotherapy, Allied Health Professionals' Function, Karolinska University Hospital; C. Fridén, Associate Professor, Division of Physiotherapy, Department of Neurobiology, Care Sciences and Society, Karolinska Institutet;
I. Demmelmaier, Associate Professor, Division of Physiotherapy, Department of Neurobiology, Care Sciences and Society, Karolinska Institutet; G. Bergström, Associate Professor, Unit of Intervention and Implementation Research for Worker Health, Institute of Environmental Medicine, Karolinska Institutet; I.E. Lundberg, Professor, Rheumatology Unit, Department of Medicine, Karolinska University Hospital, Solna, Karolinska Institutet; T. Nessen, PhD, Division of Physiotherapy, Department of Neurobiology, Care Sciences and Society, Karolinska Institutet; A.B. Dufour, PhD, Division of Physiotherapy, Department of Neurobiology, Care Sciences and Society, Karolinska Institutet, Harvard Medical School, and Beth Israel Deaconess Medical Center; C.H. Opava, Professor, Division of Physiotherapy, Department of Neurobiology, Care Sciences and Society, Karolinska Institutet, and Department of Rheumatology, Karolinska University Hospital.

Address correspondence to Prof. C.H. Opava, Karolinska Institutet, Department of Neurobiology, Care Sciences and Society, Division of Physiotherapy, 23100, SE-141 83 Huddinge, Sweden. E-mail: christina.opava@ki.se

Accepted for publication February 6, 2018.

Personal non-commercial use only. The Journal of Rheumatology Copyright @ 2018 . All rights reserved. 
muscle-strengthening activities are recommended for a minimum of 2 days each week ${ }^{3}$. HEPA might be particularly important to reduce the increased risk of cardiovascular disease and early mortality seen in rheumatoid arthritis $(\mathrm{RA})^{4}$. Nevertheless, a majority of people with RA do not maintain regular physical activity 5,6 .

The value of therapeutic exercise, a subset of physical activity, in preventing disability in RA is widely recognized ${ }^{7}$. While therapeutic exercise is often performed in hospitals and other healthcare facilities under supervision of physiotherapists, HEPA is mainly performed in an everyday context. HEPA support programs tailored to the needs of people with RA might help overcome disease-specific barriers related to impairment and activity limitations. A number of randomized controlled trials investigating the outcome of interventions to promote physical activity in RA have been performed ${ }^{8,9,10,11,12}$, but only $2^{9,11}$ used HEPA programs for a minimum of 12 months and investigated HEPA maintenance over another 12 months ${ }^{13,14}$. Neither study reported levels of maintained HEPA at 2-year followup. Further, new HEPA studies should look at barriers to participation, use behavior change theory and behavior change techniques as well as multiple measures of exercise adherence, and determine which intervention components truly had a positive effect ${ }^{15,16}$.

In the PARA 2010 study, we included a well-defined sample of persons with $\mathrm{RA}^{17}$ and developed a 2-year outsourced HEPA support program aiming at adoption and longterm maintenance of HEPA ${ }^{18}$. Evaluation after 1 year indicated high retention and reasonable adherence. The program was perceived as feasible, and self-reported HEPA levels, health perception, and physical capacity increased $^{19,20}$. To our knowledge, no previous study has reported on outcomes of a 2-year HEPA intervention in persons with RA.

The aims of our present study were to describe changes of HEPA levels, general health perception, and functioning during the second year of a 2-year HEPA support program, investigate aspects of adherence and response, and describe the perceived value of the program.

\section{MATERIALS AND METHODS}

Design. Our report describes the second year of a 2-year intervention in a prospective cohort study (www.isrctn.com/ISRCTN25539102) ${ }^{18}$.

Participants. Patients diagnosed with $\mathrm{RA}^{21}$ were recruited from the Swedish Rheumatology Quality Registers (SRQ) from October to December 2010. There were 1932 persons aged 18-75 years, independent in daily living [Health Assessment Questionnaire Disability Index (HAQ-DI) $\leq 2]^{22}$, interested in participating in organized physical activity, fluent in Swedish, and not already maintaining ( $>6$ mos) recommended levels of HEPA at start of the 2-year intervention. Of these, 220 entered the program and 194 completed the first intervention year. The selection procedure ${ }^{17}$ and dropout analysis for the first intervention year ${ }^{19}$ have been reported previously. Our present study reports on the 177 participants who provided self-reported data and/or were assessed for physical performance at both 1- and 2-year assessments.
Intervention. The intervention program included 3 main components ${ }^{18}$ to promote HEPA according to recommendations ${ }^{3}$ : (1) at least 2 weekly strength training sessions; (2) physical activity of at least moderate intensity for $\geq 30 \mathrm{~min}$ for the 5 remaining days of the week; and to support HEPA, (3) support group sessions using weekly goal-setting, planning, and followup according to social cognitive theory ${ }^{23}$.

Strength training was provided as circuit training at 9 assigned training centers in 6 Swedish cities. Study participants committed to pay a fee for a 1 -year membership, allowing them to drop in whenever they preferred during opening hours. A circuit consisted of 5 devices for strength training of major muscle groups. Study participants, like any other member, joined the circle by selecting a free station and then moved around the circle to complete 3 laps, resulting in $3 \times 10$ repetitions for each muscle group. At the start of the 2-year intervention, a physiotherapist instructed each participant on how to perform efficient exercise and was then available for consultations once a week, at fixed times, during the first year. Trained fitness instructors were always available at the centers. For the second year, membership could be continued at the assigned centers or at any other training facility. Pedometers and access to a Web page for step registration were provided to each participant and use of a self-administered walk-test to monitor aerobic capacity was taught and recommended ${ }^{24}$.

The maximum number of biweekly support group meetings offered during the first year varied from 20 to 22 , depending on different logistics at the participating sites. They were guided by physiotherapists from 6 rheumatology clinics ( 8 sites) trained within the study to encourage the adoption and maintenance of HEPA $^{25}$. No such support was provided during the second intervention year, but a handbook outlining 10 optional sessions was provided and participants were encouraged to take charge of the group sessions.

Assessments. Participants were assessed at baseline and after 1 and 2 years, with data retrieved from the SRQ, patient files, weekly short text messages, a postal questionnaire, physical performance tests, and anthropometrics ${ }^{18}$. Physical therapists, independent from the intervention, were trained to administer the questionnaire and conduct all performance tests.

Background information. Sociodemographic data included age, sex, education (university vs below), income (above/below average Swedish income in 2008), and children $<18$ years at home (yes/no). Disease-related data included disease duration and comorbidities (respiratory, cardiovascular, neurological and psychiatric disease, diabetes mellitus, or other).

Physical activity. Two weekly text messages were sent to monitor each participant's adherence. One concerned the number of circuit training sessions performed in the past week and the other the number of additional days with physical activity performed on at least a moderate intensity level for $\geq 30$ minutes $^{26}$. The physiotherapists reported participants' attendance at support group meetings during the first year, but no reports on the number of group sessions attended were collected during the second year.

Self-reported current (past week) HEPA was assessed with the short form of the International Physical Activity Questionnaire, assessing overall physical activity during the past week without separating aerobic physical activity from muscle strength training ${ }^{27}$. Maintained ( $>6$ mos) HEPA was assessed with the Exercise Stage Assessment Instrument (ESAI) ${ }^{28}$. The original ESAI was modified from 1 to 2 items to suit the aims of our present study: 1 item defining aerobic physical activity as that of moderate intensity for $\geq 30 \mathrm{~min}$ for at least 5 days/week, and 1 item on muscle strength training at least twice weekly. Both items were followed by the question, "Are you physically active according to this description?"

General health perception. General health perception (primary response variable) was rated on a visual analog scale (VAS) ${ }^{29}$.

Functioning. Pain ${ }^{30}$ and fatigue ${ }^{31}$ were rated on VAS. Quality of life was assessed with the EuroQol (EQ-5D) thermometer ${ }^{32}$ and activity limitation with the HAQ-DI ${ }^{22}$. Psychosocial variables were assessed with the Exercise Self-Efficacy Scale (secondary response variable) ${ }^{33}$, modified Fear-Avoidance Beliefs Questionnaire (secondary response variable) ${ }^{34}$, Social Support for Exercise Behaviors Scales ${ }^{35}$, and 2 study-specific items 
concerning outcome expectations for physical activity on longterm health and current RA symptoms, respectively. Maximal oxygen uptake $\left(\mathrm{VO}_{2 \max }\right)$ was estimated from a submaximal bicycle ergometer test ${ }^{36}$, lower limb function was assessed with the Timed-Stands Test ${ }^{37}$, and maximum grip strength with the Grippit device ${ }^{38}$ (secondary response variables). Anthropometric data on body mass index, waist circumference, and blood pressure (systolic and diastolic) were collected.

Perceived value of HEPA program. Perceptions related to HEPA maintenance during the second intervention year were assessed with a 10-item questionnaire developed specifically for our present study. Response options were categorical or rated on ordinal scales (1-5).

Data management and analyses. Differences between those who completed both the 1- and 2-year assessments and the 17 dropouts were examined using Student $t$ test for continuous variables and chi-squared tests for categorical variables. Descriptive statistics were calculated for 1-year measurements using means (SD) for continuous variables and proportions for categorical variables. Because the majority of participants reported a " 10 " for both items concerning outcome expectations, they were dichotomized into 10 versus $<10$ for analysis.

Changes from end of the first intervention year to end of the second year were examined using generalized linear models. Using the 2 observations, at 1 year and at the end of the second year, $\beta$ coefficients and standard errors were calculated using a mixed model approach with a subject effect.

For analysis of adherence, participants were categorized into adherers or non-adherers during the second year based on their $50 \%, 70 \%$, and $90 \%$ participation in circuit training sessions and total days of HEPA (circuit training and aerobic activity), respectively. Adherence categorization for group meetings was based on $50 \%, 70 \%$, and $90 \%$ attendance. Changes in the 6 response variables were calculated between the end of the first intervention year and the end of the second. Student $t$ test was used to compare the mean changes in the response variables in adherers versus non-adherers.

For analysis of response, participants were categorized into responders and nonresponders based on $10 \%, 20 \%$, and $30 \%$ second-year improvements in each of the 6 response variables. Student t test was used to examine the differences in mean adherence to each of the 3 program components in the responders versus nonresponders.

A total response variable was based on unchanged or improved values during the second year in perceived health and at least 2 of the 3 secondary response variables presumed to reflect HEPA performance. Using this response variable, participant characteristics at the end of the first year were compared in responders versus nonresponders using Student t test or the chi-squared test. This test was also used to compare responders to non-responders regarding their participation in circuit training, and total days with HEPA and in support group meetings.

SAS/STAT version 9.3 (SAS Institute) was used for all analyses. Alpha levels were set to 0.05 for presentation of descriptive data for the 2-year change and 1-year differences by responder status, while $\alpha$ levels were set at 0.01 to account for multiple testing in the study of different levels of adherence and response.

Ethical approval. The Stockholm Regional Ethical Review Board approved the study (2010/1232-31/1). Information about the study along with the questionnaires was mailed to all participants. They consented to participate by filling out and returning the questionnaires. Those consenting received additional practical information and consented by filling out and returning a form with the desired site and time for their HEPA program participation.

\section{RESULTS}

The mean age of the 177 participants was 60 years (SD 8.9), mean disease duration was 12 years (SD 9.2), and 144 (81\%) were female. The 177 participants did not differ from the 17 two-year dropouts regarding age, disease duration, or proportion of women $(p>0.05)$. Neither did they differ in health perception, timed standing, or grip strength $(\mathrm{p}>0.05)$, but they had significantly better estimated mean maximal oxygen uptake (30 vs 22 $\mathrm{ml} / \mathrm{kg} / \mathrm{min}, \mathrm{p}=0.0207$ ).

Physical activity. The mean number of reported circuit training sessions was 37 (SD 33.9), and the mean number of total days with HEPA was 179 (79.2). The mean number of support group attendance was 10 (6.2). The proportions of participants meeting current HEPA had decreased from $82 \%$ during the first year to $75 \%(\mathrm{p}=0.0141)$. The proportions reaching maintained HEPA decreased from $41 \%$ to $27 \%$ $(\mathrm{p}<0.0001)$.

Functioning. Deteriorations in quality of life and activity limitation were observed at the end of the second year compared to the first-year outcome. The proportions of participants with high expectations for longterm and short-term outcomes of physical activity increased. Deterioration of grip strength and reduction of systolic blood pressure and waist circumference occurred during the second year, while all other variables remained unchanged (Table 1).

Adherence and response. Different levels of adherence to any of the 3 HEPA program components during the second year were not statistically significantly related $(p>0.05)$ to change in any of the 6 response variables (data not shown). Different levels of response, neither total nor single-variable, were statistically significantly related to adherence to any of the HEPA program components except for timed standing, which improved among those having participated less in support group meetings (Table 2).

The mean number of reported circuit training sessions was 41 (35.3) among second-year total responders $(\mathrm{n}=54)$ and 35 (33.4) among nonresponders $(\mathrm{n}=105, \mathrm{p}=0.2708)$. Their mean number of total days with HEPA was 194 (80.8) and 171 (76.9), respectively ( $\mathrm{p}=0.0828)$, and the mean number of registered support group meetings 12 (6.1) and 10 (6.1), respectively $(\mathrm{p}=0.0943)$. Total second-year responders more frequently reached HEPA levels, perceived better health, and performed better in timed standing at the end of Year 1 compared to nonresponders. No other differences were observed between second-year responders and nonresponders (Table 3).

Perceived value of program. Of the participants, 29\% reported regular participation in support group meetings during the second year, and another $17 \%$ reported occasional attendance. The reported content of the group meetings ranged from physical activity performance (17\%), having meals together (33\%), and miscellaneous (49\%) including pep talks, walk tests to monitor aerobic capacity, and circuit training; group meetings also included social activities. Of those participating in group meetings, $75 \%$ had invited their physiotherapist on some occasion. The structured handbook had been used regularly by $19 \%$ and occasionally by $36 \%$. Strategies for maintenance and relapse prevention that they

Personal non-commercial use only. The Journal of Rheumatology Copyright @ 2018. All rights reserved. 
Table 1. Changes from the end of the first intervention year to the end of the second for perceived health and functioning.

\begin{tabular}{|c|c|c|c|c|c|}
\hline Variables & Year $1, \mathrm{n}$ & $\begin{array}{c}\text { Year } 1, \\
\text { Mean }(\mathrm{SD})\end{array}$ & Year 2, n & $\begin{array}{c}\text { Year 2- } \\
\text { Year } 1, \beta(\mathrm{SE})\end{array}$ & $\mathrm{p}$ \\
\hline Health, VAS, 0-100 & 171 & $26(21.8)$ & 169 & $2.94(1.55)$ & 0.0574 \\
\hline Pain, VAS, 0-100 & 174 & $24(21.3)$ & 173 & $2.13(1.53)$ & 0.1628 \\
\hline Fatigue, VAS, 0-100 & 174 & $32(24.5)$ & 173 & $0.79(1.6)$ & 0.6223 \\
\hline Quality of life, EQ-5D, 0-100 & 170 & $76(18.1)$ & 170 & $-2.87(1.39)$ & 0.0395 \\
\hline Activity limitation, HAQ-DI, 0-3 & 174 & $0.30(0.42)$ & 174 & $0.04(0.01)$ & 0.0038 \\
\hline Exercise self-efficacy, 6-60 & 167 & $33(12.0)$ & 164 & $0.01(0.96)$ & 0.9947 \\
\hline Fear avoidance beliefs, $0-24$ & 172 & $5(4.2)$ & 172 & $-0.44(0.27)$ & 0.0989 \\
\hline \multicolumn{6}{|l|}{ Social support, 0-65 } \\
\hline Family & 152 & $24(12.6)$ & 142 & $0.62(1.02)$ & 0.5454 \\
\hline Friends & 159 & $29(13.1)$ & 162 & $-0.91(1.09)$ & 0.4043 \\
\hline OE longterm health $=10, \mathrm{n}(\%)^{*}$ & 174 & $141(81)$ & 174 & $153(88)$ & 0.0186 \\
\hline OE RA symptoms $=10, \mathrm{n}(\%)^{*}$ & 174 & $76(44)$ & 174 & $97(56)$ & 0.0010 \\
\hline $\mathrm{VO}_{2 \max }, \mathrm{ml} / \mathrm{kg} / \mathrm{min}$ & 135 & $30.0(7.95)$ & 133 & $-0.73(0.45)$ & 0.1001 \\
\hline Time standing, s & 169 & $18(6.6)$ & 166 & $0.28(0.36)$ & 0.4474 \\
\hline Grip strength max, right, $n$ & 172 & $235(112.0)$ & 172 & $-7.12(3.3)$ & 0.0309 \\
\hline $\mathrm{BMI}, \mathrm{kg} / \mathrm{m}^{2}$ & 172 & $26(4.9)$ & 168 & $0.01(0.11)$ & 0.9457 \\
\hline Waist circumference, $\mathrm{cm}$ & 172 & $90(13.8)$ & 170 & $-0.85(0.32)$ & 0.0070 \\
\hline Systolic blood pressure, $\mathrm{mmHg}$ & 171 & $134(18.0)$ & 168 & $-2.33(1.11)$ & 0.0351 \\
\hline Diastolic blood pressure, $\mathrm{mmHg}$ & 171 & $82(9.1)$ & 168 & $-1.16(0.6)$ & 0.0530 \\
\hline
\end{tabular}

* Does not indicate change Year 2-Year 1, but proportions with $\mathrm{OE}=10$ and $\mathrm{p}$ values indicating changes in proportions. Alpha level set at 0.05 (shown in bold face). Health: general health perception; VAS: visual analog scale; HAQ-DI: Health Assessment Questionnaire-Disability Index; OE: outcome expectations; $\mathrm{VO}_{2 \mathrm{max}}$ : maximal oxygen uptake; RA: rheumatoid arthritis; BMI: body mass index.

Table 2. Response (1) versus no response (0) based on 3 improvement levels (10\%, 20\%, and $30 \%)$ of health perception and timed standing in relation to adherence to circuit training sessions and total days of HEPA during Year 2, and to group meeting adherence during Year 1.

\begin{tabular}{|c|c|c|c|c|c|c|c|c|c|c|}
\hline \multirow[t]{2}{*}{ Variables } & \multirow[t]{2}{*}{ Response } & \multicolumn{3}{|c|}{ Circuit Training $^{\mathrm{a}}$} & \multicolumn{3}{|c|}{ HEPA $^{b}$} & \multicolumn{3}{|c|}{ Support Group Meetings ${ }^{c}$} \\
\hline & & $\mathrm{n}$ & Mean (SD) & $\mathrm{p}$ & $\mathrm{n}$ & Mean (SD) & $\mathrm{p}$ & $\mathrm{n}$ & Mean (SD) & $\mathrm{p}$ \\
\hline \multicolumn{11}{|l|}{$\Delta$ Health } \\
\hline \multirow[t]{2}{*}{$10 \%$} & 0 & 104 & $36(33.8)$ & 0.6542 & 104 & $183(82.9)$ & 0.3700 & 107 & $11(6.4)$ & 0.8394 \\
\hline & 1 & 51 & $38(34.4)$ & & 50 & $170(69.3)$ & & 58 & $10(5.8)$ & \\
\hline \multirow[t]{2}{*}{$20 \%$} & 0 & 112 & $34(33.1)$ & 0.2991 & 111 & $181(81.0)$ & 0.5009 & 117 & $10(6.3)$ & 0.8708 \\
\hline & 1 & 43 & $41(36.0)$ & & 43 & $172(73.2)$ & & 48 & $11(5.9)$ & \\
\hline \multirow[t]{2}{*}{$30 \%$} & 0 & 120 & $36(33.6)$ & 0.7279 & 119 & $182(80.0)$ & 0.3511 & 127 & $10(6.3)$ & 0.5612 \\
\hline & 1 & 35 & $38(35.4)$ & & 35 & $168(74.4)$ & & 38 & $11(5.9)$ & \\
\hline \multicolumn{11}{|c|}{$\Delta$ Timed standing } \\
\hline \multirow[t]{2}{*}{$10 \%$} & 0 & 124 & $38(33.7)$ & 0.8775 & 123 & $183(76.7)$ & 0.3991 & 131 & $11(6.0)$ & 0.1851 \\
\hline & 1 & 29 & $37(37.1)$ & & 29 & $169(88.6)$ & & 32 & $9(6.6)$ & \\
\hline \multirow[t]{2}{*}{$20 \%$} & 0 & 144 & $38(34.0)$ & 0.5339 & 143 & $181(79.2)$ & 0.6013 & 152 & $11(6.1)$ & 0.0008 \\
\hline & 1 & 9 & $31(39.2)$ & & 9 & $167(78.0)$ & & 11 & $5(3.8)$ & \\
\hline \multirow[t]{2}{*}{$30 \%$} & 0 & 150 & $38(34.3)$ & 0.3271 & 149 & $180(79.5)$ & 0.6867 & 158 & $11(6.1)$ & $<0.0001$ \\
\hline & 1 & 3 & $19(30.6)$ & & 3 & $162(52.8)$ & & 5 & $3(1.9)$ & \\
\hline
\end{tabular}

a Circuit training recommended for Year $2 \geq 104 .{ }^{\mathrm{b}}$ Possible total HEPA days including both circuit training and moderate-intensity aerobic physical activity $=365$. ${ }^{\mathrm{c} S u p p o r t}$ group meetings during Year $1=20-22$. Alpha level set at 0.01 (shown in bold face). HEPA: health-enhancing physical activity; Health: general health perception.

had learned during the first intervention year were reportedly used by $35 \%$ of the participants. The perceived value of different HEPA program components was highest for circuit training, daily physical activity, and short text message reminders, while step registration and walk tests to self-monitor aerobic capacity were perceived as of the least value (Table 4).

\section{DISCUSSION}

To our knowledge, our study is the first to evaluate a 2-year HEPA program in people with RA, which was outsourced to public gyms. Our results indicate what outcomes to expect and clearly illustrate the challenges of evaluating complex, nonpharmacological interventions in contexts other than healthcare facilities. 
Table 3. End of Year 1 characteristics of participants with improved/unchanged outcomes (total responders) and deteriorated outcomes (total nonresponders) at the end of Year 2 as compared to the end of Year 1. Values are mean (SD) unless otherwise specified.

\begin{tabular}{|c|c|c|c|}
\hline Characteristics & Responders, $\mathrm{n}=54$ & Nonresponders, $\mathrm{n}=105$ & $\mathrm{p}$ \\
\hline Age, yrs & $59(9.6)$ & $61(8.4)$ & 0.1784 \\
\hline Females, n (\%) & $46(85)$ & $81(77)$ & 0.2310 \\
\hline University education, $\mathrm{n}(\%)$ & $34(63)$ & $50(48)$ & 0.0664 \\
\hline Income above average, $\mathrm{n}(\%)$ & $42(78)$ & $70(67)$ & 0.1694 \\
\hline Children at home, n (\%) & $12(22)$ & $12(11)$ & 0.0718 \\
\hline Disease duration, yrs & $11(8.3)$ & $13(9.5)$ & 0.3003 \\
\hline \multicolumn{4}{|l|}{ Comorbidites, n (\%) } \\
\hline 0 & $23(43)$ & $46(44)$ & 0.3686 \\
\hline 1 & $8(15)$ & $24(23)$ & 0.3686 \\
\hline $2+$ & $23(43)$ & $35(33)$ & 0.3686 \\
\hline Current HEPA, n (\%) & $49(91)$ & $80(76)$ & 0.0421 \\
\hline Maintained HEPA, n (\%) & $27(50)$ & $62(59)$ & 0.2610 \\
\hline Health, VAS, 0-100 & $19(17.4)$ & $28(23)$ & 0.0060 \\
\hline Pain, VAS, 0-100 & $21(17.4)$ & $25(23)$ & 0.2235 \\
\hline Fatigue, VAS, 0-100 & $29(22.4)$ & $34(25.7)$ & 0.2535 \\
\hline Quality of life, EQ-5D, 0-100 & $78(15.0)$ & $76(18.9)$ & 0.3735 \\
\hline Activity limitation, HAQ-DI, 0-3 & $0.29(0.39)$ & $0.30(0.45)$ & 0.8572 \\
\hline Exercise self-efficacy, 6-60 & $35(11.2)$ & $33(12.5)$ & 0.2571 \\
\hline Fear avoidance beliefs, $0-24$ & $5(4.2)$ & $5(4.2)$ & 0.8521 \\
\hline \multicolumn{4}{|l|}{ Social support, $0-65$} \\
\hline Family & $30(13.4)$ & $27(13.3)$ & 0.2823 \\
\hline Friends & $27(12.7)$ & $22(12.7)$ & 0.0707 \\
\hline OE longterm health $=10$ & $48(89)$ & $80(76)$ & 0.0556 \\
\hline OE RA symptoms $=10$ & $23(43)$ & $46(44)$ & 0.8834 \\
\hline $\mathrm{VO}_{2 \max }, \mathrm{ml} / \mathrm{kg} / \mathrm{min}$ & $31(9.1)$ & $29(7.5)$ & 0.2613 \\
\hline Timed standing, $\mathrm{s}$ & $16(5.6)$ & $19(7.1)$ & 0.0119 \\
\hline Grip strength max right, $n$ & $240(104.0)$ & $235(118.3)$ & 0.7527 \\
\hline $\mathrm{BMI}, \mathrm{kg} / \mathrm{m}^{2}$ & $26(5.0)$ & $27(4.9)$ & 0.2293 \\
\hline Waist circumference, $\mathrm{cm}$ & $87(14.2)$ & $91(13.4)$ & 0.1328 \\
\hline Systolic blood pressure, $\mathrm{mmHg}$ & $132(18.8)$ & $134(17.0)$ & 0.5639 \\
\hline Diastolic blood pressure, $\mathrm{mmHg}$ & $81(9.9)$ & $82(8.6)$ & 0.4143 \\
\hline
\end{tabular}

Alpha level set at 0.05 (shown in bold face). Health: general health perception; HEPA: health-enhancing physical activity; VAS: visual analog scale; HAQ-DI: Health Assessment Questionnaire-Disability Index; OE: outcome expectations; RA: rheumatoid arthritis; $\mathrm{VO}_{2 \max }$ : maximal oxygen uptake; BMI: body mass index.

Table 4. Perceived value (1-5) of HEPA program elements for maintenance of physical activity among 172 of 177 participants answering the study-specific questionnaire.

\begin{tabular}{lcc}
\hline HEPA Program Component & Median & Range \\
\hline Group support & 3 & $1-4$ \\
Handbook & 2 & $1-3$ \\
Planning & 3 & $2-4$ \\
Maintenance and relapse prevention strategies & 3 & $1-3$ \\
Circuit training & 4 & $3-5$ \\
Daily physical activity & 4 & $4-5$ \\
Pedometer & 3 & $1-4$ \\
Step registration & 1 & $1-1$ \\
Short text messages & 4 & $3-5$ \\
Walk test to self-monitor aerobic capacity & 1 & $1-3$ \\
\hline
\end{tabular}

HEPA: health-enhancing physical activity.

The 220 participants included at baseline constituted $11 \%$ of the potentially eligible participants and differed from those declining ${ }^{17}$ mainly regarding psychosocial matters.
Eighty-eight percent of the included sample completed 1-year assessments ${ }^{19}$ and $81 \%$ completed the 2-year assessments reported in this paper. The retention rate was thus reasonably good, but differences between those entering and completing the study compared to those who declined or dropped out raise questions about external validity. This has not been described in detail in previous HEPA studies but indicates that patients with RA consenting to and completing participation are not those that would likely benefit the most.

Huge variation in adherence to the program was indicated in the text messages, but most study participants established and maintained circuit training habits and HEPA levels corresponding to at least $150 \mathrm{~min}$ a week. This must be considered a good outcome and thus the HEPA goals of our study might have been set too high. The proportion of participants reporting current HEPA dropped slightly during the second year but was still 20\% higher compared to baseline. This compares very well with a previous 1 -year randomized controlled trial (RCT) of Internet-based HEPA support, in

Personal non-commercial use only. The Journal of Rheumatology Copyright @ 2018 . All rights reserved. 
which about $20 \%$ of initially sedentary participants with RA still performed HEPA on most days of the week at 2-year followup ${ }^{13}$. Further, our results indicated that maintained HEPA had reportedly been performed by $27 \%$ of our participants during the second year, which represented a reduction from Year 1, but the results were still a substantial increase from baseline, when none of our participants maintained HEPA $^{20}$. Considering the huge challenges of health behavior change, a $27 \%$ increase of maintained HEPA is a most satisfactory outcome of our program and is also considerably higher than the 7\% still performing HEPA at 2-year followup of the previous 1-year RCT of Internet-based HEPA support ${ }^{13}$. Structured use of behavior change techniques and a second year to support maintenance with a reduced program, as in our study, might thus help people with RA to maintain HEPA behavior.

Increased outcome expectations of HEPA on longterm health and RA symptoms during the second year might indicate changed cognitions related to HEPA among the participants during the maintenance phase and, in turn, positive influence on future HEPA participation ${ }^{19}$. The most likely explanations for lack of improvements, or even decline, during the second year of aerobic capacity, muscle function, activity performance, and quality of life were our participants' relatively high performance at the end of the first year ${ }^{20}$, consequently leaving little room for improvement ${ }^{39}$. Another could be that withdrawal of scheduled support from physiotherapists and peers during the second year resulted in suboptimal progression of HEPA intensity ${ }^{40,41}$. However, it is worth noting that our participants still had a high aerobic capacity compared to the general population and other studies of persons with RA of similar age $\mathrm{a}^{39,42,43,44}$, probably indicating a better cardiovascular disease (CVD) risk profile and a lower 10-year CVD risk ${ }^{44}$.

No significant relationships were observed in response and adherence. This might be partially attributed to limited statistical power, because participants were unevenly distributed over groups of adherence and response, or lack of improvements in outcome variables. Another reason might be that our expectations for $50 \%, 70 \%$, and $90 \%$ adherence and $10 \%, 20 \%$, and $30 \%$ outcome improvements were too optimistic for nonpharmacological interventions.

Our inclusion of behavior change techniques recommended for interventions aiming at adoption and maintenance of HEPA behavior ${ }^{45,46}$ was not highly valued by the majority of our participants. It may be that the physical therapists, although trained to encourage participants to practice self-regulation, failed to target autonomous motivation that is important for the maintenance phase ${ }^{12,46}$. Further, guidance of support group meetings and tailoring the content and support to individual needs and preferences represented challenges to physiotherapists ${ }^{25}$, which most likely influenced the HEPA maintenance in our study. Interestingly, a previous study of views on delivery of HEPA programs among patients with RA indicated that group-based programs, peer support, expert physiotherapist input, self-set goals, and coping strategies would support adherence ${ }^{47}$. Because those things are very much in line with what we did in our study, it seems easier said than done.

The strengths of our study are a well-defined sample, a longterm perspective, and a combination of data collection methods, including validated questionnaires, short text messages, and performance tests. In particular, the use of continuous short text messages might reduce recall bias, whereas the social desirability related to self-reporting is still a problem ${ }^{48}$. The major limitation of our study is its cohort design and the subsequent uncertainty in attributing the observed changes in behavior, health, and functioning entirely to the HEPA program. However, while randomized controlled designs reduce threats to internal validity, cohort studies may, particularly in those with longterm perspective, reduce threats to external validity, with less inclusion bias and better attrition and adherence. Objective measures of HEPA behavior would be desirable ${ }^{49}$ but are not feasible for monitoring hundreds of participants over 2 years, and using them for shorter periods during longterm interventions might cause social desirability bias because participants cannot be blinded to whether they carry them during a particular period of time. Our results from the recruitment process for this HEPA program ${ }^{17}$ and the present 2-year evaluation indicate that more effort should be put into recruiting and retaining individuals with low aerobic capacity, fatigue, and negative attitudes toward physical activity, because they are likely to benefit most from HEPA programs. Further, it is important that HEPA goals are tailored to each individual and are not too ambitious. Gradual withdrawal of support seems to increase HEPA maintenance and should be incorporated in clinical programs. Short text messages are feasible to supervise, but also to prompt, HEPA adherence ${ }^{20}$.

Future studies should further investigate appropriate education and training of physiotherapists to provide behavior change support. Also, the perceptions of people with RA and negative attitudes toward physical activity need further study. Our study provides a novel model for data analysis of adherence and response, to provide a more individualized picture in studies on complex nonpharmacological interventions with a pragmatic design. It could be further developed and tested as a potential parallel to calculation of dose-response models in drug studies ${ }^{50}$. Although maintained HEPA decreased during the second intervention year, about one-fourth of our study participants not obtaining adequate HEPA at baseline sustained HEPA behaviors in line with international guidelines after 2 years. It remains unclear whether improvement in health and functioning relates to the HEPA program and its different components.

\section{ACKNOWLEDGMENT}

We acknowledge the kind contribution of the study participants, the Swedish Rheumatology Quality Registers, and the PARA Study Group.

Personal non-commercial use only. The Journal of Rheumatology Copyright @ 2018. All rights reserved. 


\section{REFERENCES}

1. World Health Organization. Physical activity and adults. [Internet. Accessed March 28, 2018.] Available from: www.who.int/ dietphysicalactivity/factsheet_adults/en/index.html

2. Haskell WL, Lee IM, Pate RR, Powell KE, Blair SN, Franklin BA, et al. Physical activity and public health: updated recommendation for adults from the American College of Sports Medicine and the American Heart Association. Med Sci Sports Exerc 2007; 39:1423-34.

3. Nelson ME, Rejeski WJ, Blair SN, Duncan PW, Judge JO, King AC, et al. Physical activity and public health in older adults: recommendation from the American College of Sports Medicine and the American Heart Association. Med Sci Sports Exerc 2007;39:1435-45.

4. Zegkos T, Kitas G, Dimitroulas T. Cardiovascular risk in rheumatoid arthritis: assessment, management and next steps. Ther Adv Musculoskelet Dis 2016;8:86-101.

5. Demmelmaier I, Bergman P, Nordgren B, Jensen I, Opava CH. Current and maintained health-enhancing physical activity in rheumatoid arthritis: a cross-sectional study. Arthritis Care Res 2013;65:1166-76.

6. Tierney M, Fraser A, Kennedy N. Physical activity in rheumatoid arthritis: a systematic review. J Phys Act Health 2012;9:1036-48.

7. Swärdh E, Brodin N. Effects of aerobic and muscle strengthening exercise in adults with rheumatoid arthritis: a narrative review summarising a chapter in physical activity in the prevention and treatment of disease (FYSS 2016). Br J Sports Med 2016;50:362-7.

8. Brus HL, van de Laar MA, Taal E, Rasker JJ, Wiegman O. Effects of patient education on compliance with basic treatment regimens and health in recent onset active rheumatoid arthritis. Ann Rheum Dis 1998;57:146-51.

9. van den Berg MH, Ronday HK, Peeters AJ, le Cessie S, van der Giesen FJ, Breedveld FC, et al. Using internet technology to deliver a home-based physical activity intervention for patients with rheumatoid arthritis: a randomized controlled trial. Arthritis Rheum 2006;55:935-45.

10. Mayoux-Benhamou A, Giraudet-Le Quintrec JS, Ravaud P, Champion K, Dernis E, Zerkak D, et al. Influence of patient education on exercise compliance in rheumatoid arthritis: a prospective 12-month randomized controlled trial. J Rheumatol 2008;35:216-23.

11. Brodin N, Eurenius E, Jensen I, Nisell R, Opava CH; PARA study group. Coaching patients with early rheumatoid arthritis to healthy physical activity: A multicenter, randomized, controlled study. Arthritis Rheum 2008;59:325-31.

12. Knittle K, De Gucht V, Hurkmans E, Peeters A, Ronday K, Maes S, et al. Targeting motivation and self-regulation to increase physical activity among patients with rheumatoid arthritis: a randomised controlled trial. Clin Rheumatol 2015;34:231-8.

13. Hurkmans EJ, van den Berg MH, Ronday KH, Peeters AJ, le Cessie S, Vlieland TP. Maintenance of physical activity after Internet-based physical activity interventions in patients with rheumatoid arthritis. Rheumatology 2010;49:167-72.

14. Sjöquist ES, Brodin N, Lampa J, Jensen I, Opava CH; PARA Study Group. Physical-activity coaching in everyday practice of patients with rheumatoid arthritis. A long-term follow-up. Musculoskel Care 2011;9:75-85.

15. Ezzat AM, MacPherson K, Leese J, Li LC. The effects of interventions to increase exercise adherence in people with arthritis: a systematic review. Musculoskeletal Care 2015;13:1-18.

16. Larkin L, Gallagher S, Cramp F, Brand C, Fraser A, Kennedy N. Behaviour change interventions to promote physical activity in rheumatoid arthritis: a systematic review. Rheumatol Int 2015;35:1631-40.

17. Nordgren B, Fridén C, Demmelmaier I, Opava CH. Who makes it to the base? Selection procedure for a physical activity trial targeting people with RA. Arthritis Care Res 2014;66:662-70.

18. Nordgren B, Fridén C, Demmelmaier I, Bergström G, Opava CH. Long-term health-enhancing physical activity in rheumatoid arthritis - the PARA 2010 study. BMC Public Health 2012;12:397.

19. Nordgren B, Fridén C, Demmelmaier I, Bergström G, Lundberg IE, Dufour AB, et al; PARA Study Group. An outsourced health-enhancing physical activity programme for people with rheumatoid arthritis: exploration of adherence and response. Rheumatology 2015;54:1065-73.

20. Demmelmaier I, Lindkvist $\AA$, Nordgren B, Opava CH. "A gift from heaven" or "This was not for me". A mixed methods approach to describe experiences of participation in an outsourced physical activity program for persons with rheumatoid arthritis. Clin Rheumatol 2015;34:429-39.

21. Arnett FC, Edworthy SM, Bloch DA, McShane DJ, Fries JF, Cooper NS, et al. The American Rheumatism Association 1987 revised criteria for the classification of rheumatoid arthritis. Arthritis Rheum 1988;31:315-24.

22. Fries JF, Spitz P, Kraines RG, Holman HR. Measurement of patient outcome in arthritis. Arthritis Rheum 1980;23:137-45.

23. Bandura A. Social cognitive theory: an agentic perspective. Annu Rev Psychol 2001;52:1-26.

24. Nordgren B, Fridén C, Jansson E, Österlund T, Grooten W, Opava $\mathrm{CH}$, et al. Criterion validation of two submaximal aerobic fitness tests, the self-monitoring Fox-walk test and the Åstrand cycle test in people with rheumatoid arthritis. BMC Musculoskelet Disord 2014; $15: 305$.

25. Nessen T, Opava CH, Martin C, Demmelmaier I. From clinical expert to guide: experiences from coaching people with rheumatoid arthritis to increased physical activity. Phys Ther 2014;94:644-53.

26. Shiffman S, Stone AA, Hufford MR. Ecological momentary assessment. Annu Rev Clin Psychol 2008;4:1-32.

27. Craig CL, Marshall AL, Sjöström M, Bauman AE, Booth ML, Ainsworth BE, et al. International physical activity questionnaire 12 -country reliability and validity. Med Sci Sports Exerc 2003;35:1381-95.

28. Burbank PM, Riebe D. Promoting exercise and behavior change in older adults: interventions with the transtheoretical model. New York: Springer; 2002.

29. Felson DT, Anderson JJ, Boers M, Bombardier C, Chernoff M, Fried B, et al. The American College of Rheumatology preliminary core set of disease activity measures for rheumatoid arthritis clinical trials. The Committee on Outcome Measures in Rheumatoid Arthritis Clinical Trials. Arthritis Rheum 1993;36:729-40.

30. Huskisson EC. Measurement of pain. J Rheumatol 1982;9:768-9.

31. Wolfe F. Fatigue assessments in rheumatoid arthritis: comparative performance of visual analog scales and longer fatigue questionnaires in 7760 patients. J Rheumatol 2004;31:1896-902.

32. Hurst NP, Kind P, Ruta D, Hunter M, Stubbings A. Measuring health-related quality of life in rheumatoid arthritis: validity, responsiveness and reliability of EuroQol (EQ-5D). Br J Rheumatol 1997;36:551-9.

33. Nessen T, Demmelmaier I, Nordgren B, Opava CH. The Swedish Exercise Self-Efficacy Scale (ESES-S): reliability and validity in a rheumatoid arthritis population. Disabil Rehabil 2015;37:2130-4.

34. Buer N, Linton SJ. Fear-avoidance beliefs and catastrophizing: occurrence and risk factor in back pain and ADL in the general population. Pain 2002;99:485-91.

35. Sallis JF, Grossman RM, Pinski RB, Patterson TL, Nader PR. The development of scales to measure social support for diet and exercise behaviors. Prev Med 1987;16:825-36.

36. Åstrand P, Rohdal K, Dahl H, Stromme S. Textbook of work physiology: physiological bases of exercise, 4th rev. Champaign: Human Kinetics; 2003.

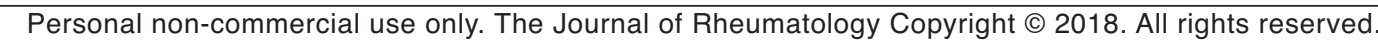


37. Newcomer KL, Krug HE, Mahowald ML. Validity and reliability of the timed-stands test for patients with rheumatoid arthritis and other chronic diseases. J Rheumatol 1993;20:21-7.

38. Nordenskiold UM, Grimby G. Grip force in patients with rheumatoid arthritis and fibromyalgia and in healthy subjects. A study with the Grippit instrument. Scand J Rheumatol 1993; 22:14-9.

39. McArdle WD, Katch FI, Katch VL. Exercise physiology: Nutrition, energy, and human performance. Philadelphia: Lippincott Williams \& Wilkins; 2010 .

40. Oja P. Dose response between total volume of physical activity and health and fitness. Med Sci Sports Exerc 2001;6 Suppl:S428-37; S452-3.

41. American College of Sports Medicine Position Stand. The recommended quantity and quality of exercise for developing and maintaining cardiorespiratory and muscular fitness, and flexibility in healthy adults. Med Sci Sports Exerc 1998;30:975-91.

42. Munsterman T, Takken T, Wittink H. Are persons with rheumatoid arthritis deconditioned? A review of physical activity and aerobic capacity. BMC Musculoskelet Disord 2012;13:202.

43. Yu CA, Rouse PC, Veldhuijzen Van Zanten JJ, Ntoumanis N, Kitas GD, Duda JL, et al. Subjective and objective levels of physical activity and their association with cardiorespiratory fitness in rheumatoid arthritis patients. Arthritis Res Ther 2015;17:59.

44. Metsios GS, Koutedakis Y, Veldhuijzen van Zanten JJ, Stavropoulos-Kalinoglou A, Vitalis P, Duda JL, et al. Cardiorespiratory fitness levels and their association with cardiovascular profile in patients with rheumatoid arthritis: a cross-sectional study. Rheumatology 2015;54:2215-20.

45. Michie S, Abraham C, Whittington C, McAteer J, Gupta S. Effective techniques in healthy eating and physical activity interventions: a meta-regression. Health Psychol 2009;28:690-701.

46. Fjeldsoe B, Neuhaus M, Winkler E, Eakin E. Systematic review of maintenance of behavior change following physical activity and dietary interventions. Health Psychol 2011;30:99-109.
47. Withall J, Haase AM, Walsh NE, Young A, Cramp F. Physical activity engagement in early rheumatoid arthritis: a qualitative study to inform intervention development. Physiotherapy 2016; 102:264-71.

48. Sallis JF, Saelens BE. Assessment of physical activity by self-report: Status, limitations, and future directions. Res Q Exerc Sport 2000;2 Suppl:S1-14.

49. Ferguson T, Rowlands AV, Olds T, Maher C. The validity of consumer-level, activity monitors in healthy adults worn in free-living conditions: a cross-sectional study. Int J Behav Nutr Phys Act 2015;12:42.

50. Felson DT, Anderson JJ, Boers M, Bombardier C, Furst D, Goldsmith C, et al. American College of Rheumatology. Preliminary definition of improvement in rheumatoid arthritis. Arthritis Rheum 1995;16:727-35.

\section{APPENDIX 1.}

Collaborators in the PARA Study Group: physical therapists Christina Eriksson, Annelie Nordström, Eva Prinzell, and Malin Wisell, Linköping University Hospital, Linköping; Birgitta Folin, Helena Heldt, Carina Sjöman, and Maria Wärfman, Linköping University Hospital, Norrköping; Eva Frykstad, Anna Moberg, Hanna Olsson, and Johanna Pettersson, Mälarsjukhuset, Eskilstuna; Anna Hallén and Sofia Sandström, Karolinska University Hospital, Solna; Anna Dahlgren and Åsa Lindkvist, Karolinska University Hospital, Huddinge; Erica Christensen, Elin Löfberg, and Sara Stråt, Danderyd University Hospital, Stockholm; Katrin Bylander, Ingrid Larsson and Maria Skogemyr, Östersund Hospital, Östersund; Sofia Blomqvist and Susan Sandberg, Sunderby Hospital, Luleå; Anna Nordin, Winternet, Boden; Emma Swärdh, Karolinska Institutet, Stockholm; Anne Marie Norén, Stockholm County Council, Stockholm, Sweden. 